\title{
Prevalence and predictive factors of chronic postsurgical pain and poor global recovery 1 year after outpatient surgery
}

Citation for published version (APA):

Hoofwijk, D. M. N., Fiddelers, A. A. A., Peters, M. L., Stessel, B., Kessels, A. G. H., Joosten, E. A., Gramke, H. F., \& Marcus, M. (2015). Prevalence and predictive factors of chronic postsurgical pain and poor global recovery 1 year after outpatient surgery. Clinical Journal of Pain, 31(12), 1017-1025. https://doi.org/10.1097/ajp.0000000000000207

Document status and date:

Published: 01/01/2015

DOI:

10.1097/ajp.0000000000000207

Document Version:

Publisher's PDF, also known as Version of record

\section{Document license:}

Taverne

\section{Please check the document version of this publication:}

- A submitted manuscript is the version of the article upon submission and before peer-review. There can be important differences between the submitted version and the official published version of record.

People interested in the research are advised to contact the author for the final version of the publication, or visit the DOI to the publisher's website.

- The final author version and the galley proof are versions of the publication after peer review.

- The final published version features the final layout of the paper including the volume, issue and page numbers.

Link to publication

\footnotetext{
General rights rights.

- You may freely distribute the URL identifying the publication in the public portal. please follow below link for the End User Agreement:

www.umlib.nl/taverne-license

Take down policy

If you believe that this document breaches copyright please contact us at:

repository@maastrichtuniversity.nl

providing details and we will investigate your claim.
}

Copyright and moral rights for the publications made accessible in the public portal are retained by the authors and/or other copyright owners and it is a condition of accessing publications that users recognise and abide by the legal requirements associated with these

- Users may download and print one copy of any publication from the public portal for the purpose of private study or research.

- You may not further distribute the material or use it for any profit-making activity or commercial gain

If the publication is distributed under the terms of Article $25 \mathrm{fa}$ of the Dutch Copyright Act, indicated by the "Taverne" license above, 


\title{
Prevalence and Predictive Factors of Chronic Postsurgical Pain and Poor Global Recovery 1 Year After Outpatient Surgery
}

\author{
Daisy M. N. Hoofwijk, MD,* Audrey A. A. Fiddelers, PhD,* \\ Madelon L. Peters, PhD, † Björn Stessel, MD, + Alfons G. H. Kessels, MD, \\ MSc,§ Elbert A. Joosten, PhD, ${ }^{*}$ Hans-Fritz Gramke, MD, PhD, ${ }^{*}$ \\ and Marco A. E. Marcus, MD, PhD*\|
}

\begin{abstract}
Objectives: To prospectively describe the prevalence and predictive factors of chronic postsurgical pain (CPSP) and poor global recovery in a large outpatient population at a university hospital, 1 year after outpatient surgery.

Materials and Methods: A prospective longitudinal cohort study was performed. During 18 months, patients presenting for preoperative assessment were invited to participate. Outcome parameters were measured by using questionnaires at 3 timepoints: 1 week preoperatively, 4 days postoperatively, and 1 year postoperatively. A value of $>3$ on an 11-point numeric rating scale was considered to indicate moderate to severe pain. A score of $\leq 80 \%$ on the Global Surgical Recovery Index was defined as poor global recovery.
\end{abstract}

Results: A total of 908 patients were included. The prevalence of moderate to severe preoperative pain was $37.7 \%$, acute postsurgical pain $26.7 \%$, and CPSP $15.3 \%$. Risk factors for the development of CPSP were surgical specialty, preoperative pain, preoperative analgesic use, acute postoperative pain, surgical fear, lack of optimism, and poor preoperative quality of life. The prevalence of poor global recovery was $22.3 \%$. Risk factors for poor global recovery were recurrent surgery because of the same pathology, preoperative pain, preoperative analgesic use, surgical fear, lack of optimism, poor preoperative and acute postoperative quality of life, and follow-up surgery during the first postoperative year.

Received for publication August 11, 2014; revised January 29, 2015; accepted December 20, 2014.

From the Departments of *Anesthesiology and Pain Treatment; §Clinical Epidemiology and Medical Technology Assessment, Maastricht University Medical Center + (a.k.a. MUMC + ); †Department of Clinical Psychological Science, Maastricht University, Maastricht, The Netherlands; \$Department of Anaesthesiology, Jessa Hospital, Hasselt, Belgium; and \|Department of Anesthesiology, ICU and Perioperative Medicine, Hamad Medical Corporation, Doha, Qatar.

Data collection, statistical analyses, data interpretation, figure creation, and writing of the paper: D.M.N.H. Study design, data collection, statistical analysis, data interpretation, and writing of the paper: A.A.A.F. Study design and writing of the paper: M.L.P. Writing of the paper: B.S. Writing of the paper: E.A.J. Study design, data interpretation, and writing of the paper: H.-F.G. Study design, data interpretation, and writing of the paper: M.A.E.M.

The department of anaesthesiology of the Maastricht University Medical Center + received payments of Grunenthal for consultancy activities on Tapentadol of M.A.E.M. The remaining authors declare no conflict of interest

Reprints: Daisy M. N. Hoofwijk, MD, Departments of Anesthesiology and Pain Treatment, Maastricht University Medical Center +, P.O. Box 5800, Maastricht 6202 AZ, The Netherlands (e-mail: d.hoofwijk@gmail.com).

Copyright (C) 2015 Wolters Kluwer Health, Inc. All rights reserved.

DOI: 10.1097/AJP.0000000000000207
Discussion: Moderate to severe CPSP after outpatient surgery is common, and should not be underestimated. Patients at risk for developing CPSP can be identified during the preoperative phase.

Key Words: outpatient surgery, chronic pain, postoperative pain, global recovery

(Clin J Pain 2015;31:1017-1025)

A cute postsurgical pain after outpatient surgery is a common problem, and both the prevalence and risk factors for the development of acute postsurgical pain have been extensively studied. ${ }^{1-8}$ The development of chronic postsurgical pain (CPSP) after outpatient surgery has been less extensively studied, even though it is a burden for the patient and society.

CPSP has been defined as pain persisting $>2$ months after surgery. ${ }^{9}$ However, in studies that investigate the problem of CPSP, follow-up times vary widely from several months to years. ${ }^{9}, 10$ The prevalence of moderate to severe CPSP varies from $10 \%$ to $50 \%$, whereas $2 \%$ to $10 \%$ of patients report severe CPSP. ${ }^{11}$ CPSP is associated with negative outcomes such as a reduced quality of life and increased health care utilization. ${ }^{12,13}$ Some specific types of surgery such as thoracotomy, lower limb amputation, joint arthroplasty, breast cancer surgery, and inguinal hernia repair have been extensively studied and have been associated with severe CPSP. ${ }^{11}$

The studies that address CPSP have mostly been performed in inpatients. ${ }^{11,14,15}$ With the exception of a few studies examining specific outpatient procedures (eg, inguinal hernia repair, breast cancer surgery), research about the presence of CPSP after outpatient surgery is scarce. The prevalence and risk factors of CPSP after outpatient surgery might be different from those of inpatient surgery for several reasons. First of all, the extent and impact of outpatient surgery can be different with regard to tissue damage and anesthetic techniques. Second, previous studies have shown that the treatment of acute postoperative pain might be less optimal for outpatients than for inpatients. ${ }^{16,17}$ This might lead to more peripheral and central sensitization and consequently more severe CPSP. Third, the psychological impact of outpatient surgery might be different (eg, less anxiety and catastrophizing), because of the disease which constitutes the indication for surgery may be less severe and because of the absence of hospital admission. In this context, it is important and justified to collect specific information about the prevalence and the predictors of CPSP 
after outpatient procedures. First of all, identifying patients at risk for developing CPSP might lead to better tailored pharmacotherapeutic and psychotherapeutic strategies to decrease the prevalence of CPSP. Secondly, more knowledge about the prevalence of CPSP after outpatient surgery will enable informing patients more accurately about this serious complication.

Global recovery after surgery measures overall functional recovery. CPSP is associated with a negative impact on the cost-effectiveness of outpatient surgery and it may cause absenteeism from work and social activities. ${ }^{14}$ However, not all patients experiencing CPSP may be functionally impaired, some may consider themselves fully recovered and participate in regular work and social activities. In contrast, others may experience suboptimal functional or emotional recovery without experiencing CPSP. Not much research regarding global recovery has been performed, but predictors for the development of CPSP might not be the same as predictors for a poor global recovery. ${ }^{18}$ The aim of this study is to prospectively describe the prevalence and predictive factors of CPSP, as well as the prevalence and predictive factors of a poor global recovery, 1 year after outpatient surgery, in a large group of outpatients treated at a university hospital.

\section{MATERIALS AND METHODS}

\section{Patients}

This study was designed as a prospective longitudinal study. It was approved by the institutional Ethics Committee of the Maastricht University Medical Center + , and all patients gave informed consent to participate. Every patient who underwent elective outpatient surgery was eligible for inclusion, regardless of the nature of the procedure. Potential participants were excluded if they were younger than 18 years, were unable to express themselves, were visually impaired, or if their understanding of the Dutch language was insufficient.

\section{Instruments}

Information was collected by means of 3 successive questionnaires; a preoperative pain questionnaire (Q1), an acute postsurgical pain questionnaire (Q2), and a CPSP questionnaire (Q3). Q1 contained questions regarding demographic factors (eg, age, sex, educational level, work status), average and present pain intensity, the influence of pain on daily activities, prescribed analgesic use, over-thecounter analgesic use, the effect of analgesic use on pain severity, and the number of visits to a medical doctor or other health care professionals. Furthermore, patients were specifically asked to only rate the pain they thought was related to the indication for the surgical procedure. All questions regarding pain were measured on an 11-point numeric rating scale (NRS; where $0=$ no pain, and $10=$ worst pain imaginable). Q1 also contained parts of 4 validated questionnaires. For 2 of these, shortened versions were used to keep the total number of questions within limits and thus avoiding patient refusal due to long questionnaires (ie, diminishing patient burden). To measure catastrophic thinking, 6 of the 13 original items of the Pain Catastrophizing Scale were used. These were the 2 questions loading highest on each of the 3 subscales (ie, items 5 and 12 for Helplessness, items 9 and 11 for Rumination, and items 6 and 13 for Magnification). The selection of these items was based on unpublished data from our previous research. ${ }^{18,19}$ The 8-item Surgical Fear Questionnaire was included to measure fear of potential consequences of surgery. Four items refer to fear of short-term consequences (eg, pain, side effects) and 4 items refer to fear of long-term consequences (eg, deterioration of health).$^{20}$ Also, 4 of the originally 10 questions of the Life Orientation Test-Revised were used to measure the personality trait optimism. ${ }^{21}$ The 4 filler questions were omitted and the 4 questions ( 2 positively phrased and 2 negatively phrased) loading highest on, respectively, the optimism and pessimism factor in a previous study by our group were selected. ${ }^{18}$ Finally, the EuroQol (EQ-5D) was used to measure 5 dimensions of quality of life (ie, mobility, self-care, usual activity, pain/discomfort, and anxiety/depression). ${ }^{22}$

Q2 contained questions regarding average and present pain intensity, the influence of pain on daily activities, prescribed and over-the-counter analgesic use, the effect of analgesic use on pain severity, visits to health care professionals, postoperative side effects, and complications (eg, nausea, vomiting, wound infections). We specifically asked the patients to only rate the pain they thought was related to the surgical procedure. Patients were not specifically asked to make a distinction between pain at rest and pain with movement. Q2 also contained the EQ-5D and the 1item Global Surgical Recovery Index (GSR), which represents a single question about the extent to which patients considered themselves recovered from the surgery ("if $100 \%$ recovery means your health is back to the same level as it was before the surgery, what percentage of recovery are you at now?"). ${ }^{18}$ The GSR has been found to correlate well with a more elaborate instrument measuring surgical recovery. ${ }^{23} \mathrm{Q} 3$ contained the same questions as $\mathrm{Q} 2$, as well as a question about the number of sick days during the past year.

\section{Procedure}

Between November 2008 and April 2010, patients planned for outpatient surgery and presenting at the outpatient clinic for preoperative assessment at the Maastricht University Medical Center + , were asked to participate in our study. The purpose and methods of the study were explained by the anesthesiologist or physician assistant performing the assessment. If consent was obtained, the patient received an envelope containing an information letter about the study, Q1, Q2, and 2 return envelopes. If no contraindications were present, the patient also received a standardized prescription for postoperative analgesics (ie, acetaminophen $1000 \mathrm{mg} 4$ times a day, with an upgrade to acetaminophen/tramadol $650 / 75 \mathrm{mg} 4$ times a day). The patient received verbal and written instructions to start with acetaminophen and to switch to acetaminophen/tramadol in case of insufficient analgesia.

Patients were instructed to complete Q1 1 week before the surgical procedure. Patients who did not return Q1 were considered to be unwilling to participate, and no further attempts to contact them were made. Q2 had to be completed 4 days after the surgery. Patients who did return Q1 but did not return Q2, were reminded by regular mail or telephone. One year after the procedure all participants received Q3 by regular mail. All clinical information (eg, ASA physical status, surgical procedure, type of anesthesia, duration of the procedure, duration of hospital stay) was acquired by systematic chart review. 


\section{Statistical Analysis}

All patients who returned both Q1 (because this questionnaire contained part of the predictor variables) and Q3 (because this contained the outcome parameters) were included in the analyses. Patient characteristics and mean pain scores were evaluated using descriptive statistics. For Q1 and Q3, average pain intensity during the last week was used, for Q2 the actual pain intensity. An NRS $>3$ was used as a cutoff value to define moderate to severe pain and an NRS $>7$ was defined as severe pain. ${ }^{24,25}$ In accordance with a previous study, a GSR $\leq 80 \%$ was defined as poor global recovery. ${ }^{18}$

Before analyzing the data for possible predictors of CPSP and poor global recovery, missing data were imputed using multiple data imputation according to the method described by van Buuren et al. ${ }^{26}$ In this method each missing value is replaced by a plausible value based on their predicted distribution. We imputed each of these missing values 10 times, leading to 10 different data sets. Results are based on the pooled outcome based on these 10 data sets. Only predictor variables were imputed, missing outcome variables were not. First, univariate logistic regression analyses were performed for each predictive variable. Only variables with a $P<0.1$ were included in the final multiple logistic regression models. Stepwise forward multiple logistic regression analyses were subsequently performed to determine which variables were predictive of CPSP and of poor global recovery. The model was constructed using 4 successive steps, based on the availability of the variables during the preoperative and postoperative phase. The first step contained the variables that are easiest to obtain, before patients visit the outpatient clinic (ie, sex, age, and surgical specialty). For the first step, a forced entry method was used. The second step contained variables that are easily obtained during the preoperative assessment (ie, ASA-level, work status, education level, previous surgery, preoperative pain, and preoperative analgesic use). The third step contained variables that are more difficult to obtain, but can still be obtained in the preoperative phase. All psychological variables were added to the model in this step because these variables require patients to fill out multiple questionnaires (ie, expected postoperative pain, surgical fear, pain catastrophizing, optimism, and preoperative quality of life). The fourth step contained all variables that can only be obtained during or after the surgery (ie, anesthetic technique, duration of the surgery, duration of the hospital admission, acute postsurgical pain, poor global recovery $4 \mathrm{~d}$ postoperative, postoperative nausea, postoperative infection, additional surgery during the first postoperative year, and postoperative quality of life). A $P$-value of $<0.05$ was considered to be statistically significant. To estimate the models' ability to discriminate between patients with and without CPSP and with good versus poor global recovery, the area under the curve (AUC) was calculated. In addition, a correlation analysis between CPSP and GSR was performed. All analyses were performed using SPSS version 20.0 (SPSS Inc, Chicago, IL) and STATA, version 11.2 (StataCorp, TX).

\section{RESULTS}

During 18 months, 2500 patients were invited to participate. Of these, 1396 patients $(56 \%)$ returned Q1. Of all

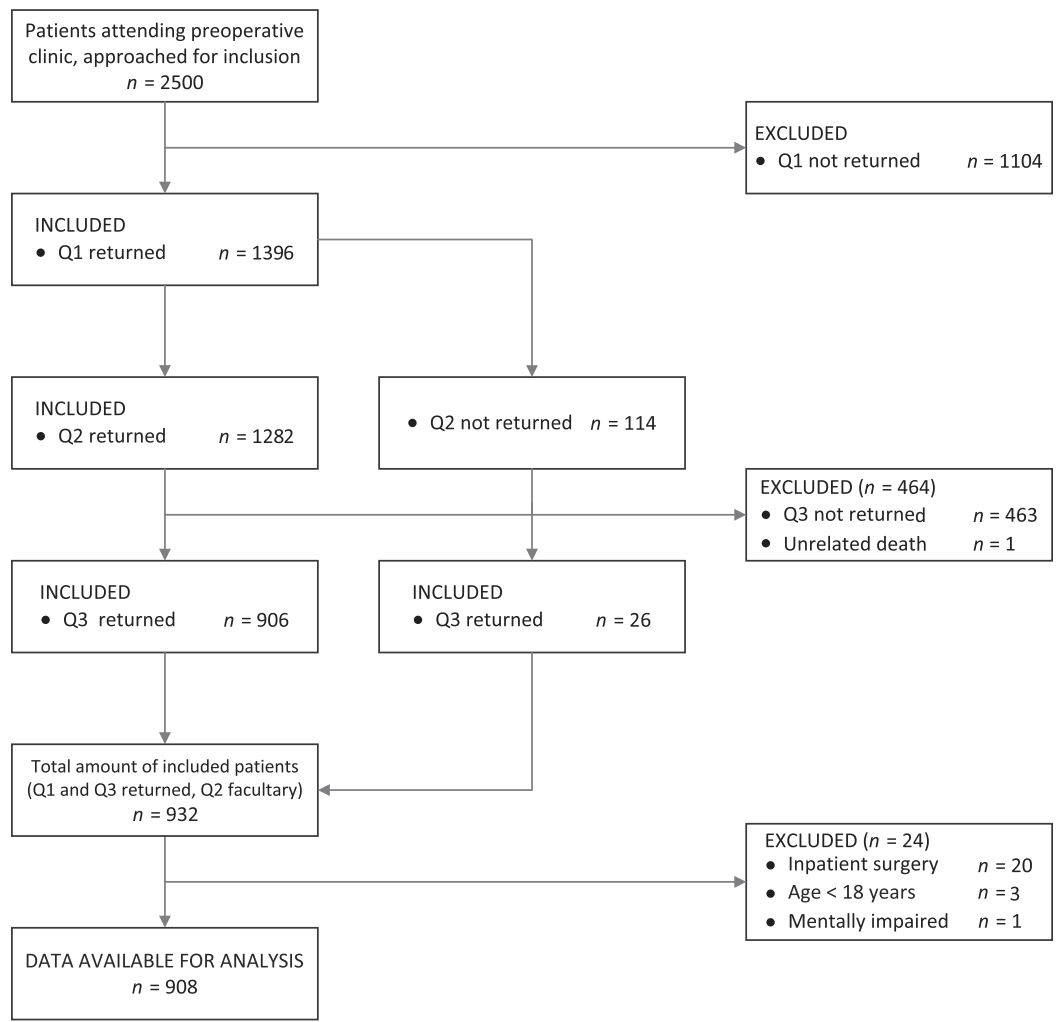

FIGURE 1. Flowchart depicting the inclusion and exclusion of the study population. Q1 = questionnaire 1 week before the surgery; $\mathrm{Q} 2$ = questionnaire 4 days after the surgery; Q3 = questionnaire 1 year after the surgery. 
patients that returned Q1, $1282(92 \%)$ returned Q2 and of these, 906 patients $(71 \%)$ returned Q3. Of the 114 patients that returned Q1 but not Q2, 26 patients $(23 \%)$ did return Q3 and were also included. Figure 1 depicts the flowchart of inclusion. Of the 932 patients that were included, 24 patients were excluded because the inclusion had not been in accordance with study protocol; 3 patients were younger than 18 years at the time of the surgery, 1 patient was mentally impaired, and 20 patients had undergone a planned inpatient procedure. This resulted in data of 908 patients for the final analyses $(65 \%$ of the patients that completed Q1 and $36 \%$ of all patients originally invited to participate). Of these patients 908 returned Q1, 883 patients returned Q2, and 908 patients returned Q3.

Procedures performed per surgical specialty are shown in Table 1. Patient characteristics are shown in Table 2. Because the patient characteristics were calculated before missing values were imputed, the results are presented as absolute numbers and percentages, and do not always add up to a total of 908 patients. A small majority of patients were female $(56.4 \%)$ and the mean age was 53 years (range, 18 to $88 \mathrm{y}$ ). The average duration of surgery was 49 minutes. Most patients $(n=716)$ received general anesthesia, a small number received regional anesthesia (eg, spinal anesthesia, peripheral nerve blocks, intravenous regional anesthesia, retrobulbar, or sub-Tenon block) in addition to or instead of general anesthesia. Of all patients, $575(63.3 \%)$ were treated on an ambulatory basis, and $310(34.1 \%)$ in terms of a short-stay admission $(<24 \mathrm{~h})$. Twenty-three patients $(2.6 \%)$ had to stay in hospital for $>24$ hours (15 patients stayed for $3 \mathrm{~d}, 6$ patients for $4 \mathrm{~d}$, and 2 patients for $5 \mathrm{~d}$ ) because of unforeseen complications. Of all patients, 67 patients $(7.4 \%)$ underwent another surgical procedure during the first year after the surgery. This second surgery was related to the original procedure in 42 patients $(62.7 \%)$.

\section{Prevalence of Pain}

A substantial number of patients $(n=334 ; 37.7 \%)$ experienced moderate to severe pain during the week before completing Q1. Four days after surgery, 235 patients $(26.7 \%)$ experienced moderate to severe pain, and 1 year after surgery this was the case for 139 patients $(15.3 \%)$. A total of 29 patients $(3.2 \%)$ experienced severe CPSP.

Figure 2 shows the percentages of patients with moderate to severe preoperative, acute postoperative, and CPSP for the different surgical specialties. During both the preoperative phase and the postoperative phase, orthopedic and general surgical procedures were most often associated with moderate to severe pain. Preoperative pain was rated as an NRS $>3$ by $71.5 \%$ of orthopedic patients and by $41.4 \%$ of general surgical patients. Postoperatively, $41.2 \%$ and $30.5 \%$ of these patients scored an NRS $>3$. Orthopedic procedures were also most often associated with moderate to severe CPSP; $34.5 \%$ of the orthopedic patients scored an NRS $>3$ one year after the surgery. Other procedures that were relatively often associated with CPSP were general surgical and plastic surgical procedures. Ophthalmologic, urologic, and gynecologic procedures resulted in the lowest pain scores at all 3 measuring points. The prevalences of moderate to severe CPSP for the more extensively studied outpatient procedures were $13.1 \%$ for inguinal hernia repair, $10.0 \%$ for breast surgery, $9.6 \%$ for general abdominal procedures, and $10.0 \%$ for laparoscopic cholecystectomy.
TABLE 1. Procedures Performed by Each Surgical Specialty

Ophthalmology $(\mathrm{n}=70)$

Cataract surgery/vitrectomy (49)

Strabismus surgery (11)

Dacrocystorhinostomy (5)

Other (5)

Gynecology $(\mathrm{n}=70)$

Hysteroscopy (33)

Laparoscopic sterilization/ovariectomy (20)

Surgical abortion (7)

Vulva condylomata/Bartholin gland (5)

Diagnostic laparoscopy (3)

Uterine suspension surgery (2)

General surgery $(\mathrm{n}=271)$

Inguinal hernia repair (60)

Lumpectomy (37)

Anal surgery (35)

Laparoscopic cholecystectomy (30)

Hardware removal (21)

Umbilical/epigastric hernia repair (20)

Skin biopsy/ganglion/lipoma (14)

Varicectomy (11)

Mastectomy/axillary lymph node dissection (8)

Tenolysis (5)

Carpal tunnel release (3)

Other (27)

ENT surgery $(\mathrm{n}=130)$

Laryngoscopy (31)

Tympanoplasty/stapedectomy (18)

Cochlear implantation (17)

Nasal polipectomy (16)

Tonsillectomy (10)

Bone anchored hearing aid (9)

Mastoidectomy (6)

Nasal septum correction (4)

Other (19)

Urology $(n=55)$

Brachytherapy prostate (26)

Scrotal surgery (11)

Uterine suspension surgery (11)

Other (7)

Plastic surgery $(\mathrm{n}=96)$

Dupuytren fasciotomy (25)

Breast reduction (11)

Surgical correction of scar (9)

Tenolysis (9)

Replacement of breast implants (8)

Carpal tunnel release (7)

Skin biopsy/ganglion/lipoma (7)

Breast augmentation (6)

Liposuction (3)

Other (11)

Orthopedic surgery $(\mathrm{n}=194)$

Arthroscopy knee/meniscectomy (112)

Shoulder surgery (23)

Hallux valgus correction (17)

Tenolysis (12)

Hardware removal (5)

Skin biopsy/ganglion/lipoma (5)

Other (20)

Other $(\mathrm{n}=22)$

Neurosurgery (1)

Dermatology (4)

Dental surgery (17)

\section{Predictors of CPSP}

Table 3 shows the logistic regression analysis for CPSP and poor global recovery. No colinearity existed for any of the variables included. ASA-level, work status, educational 


\begin{tabular}{lc}
\hline TABLE 2. Patient Characteristics & \\
\hline & N (\%) \\
\hline Age (y) & \\
$\quad<45$ & $266(29.3)$ \\
$45-59$ & $295(32.5)$ \\
$>59$ & $347(38.2)$ \\
Sex & \\
Male & $396(43.6)$ \\
Female & $512(56.4)$ \\
Educational background & \\
Elementary school & $54(6.0)$ \\
Intermediate & $656(73.1)$ \\
Higher degree, university & $187(20.8)$ \\
Work situation & \\
Working & $591(65.2)$ \\
Not working & $316(34.8)$ \\
Preoperative pain & \\
NRS 0-3 & $553(62.3)$ \\
NRS 4-10 & $334(37.7)$ \\
Preoperative analgesic use & \\
Yes & $220(24.5)$ \\
No & $677(75.5)$ \\
ASA physical status & \\
I & $444(50.0)$ \\
II & $405(45.6)$ \\
III & $39(4.4)$ \\
Type of anesthesia & \\
General & $716(79.0)$ \\
Locoregional & $143(15.8)$ \\
General and locoregional & $47(5.2)$ \\
\hline
\end{tabular}

NRS indicates numeric rating scale.

level, previous surgery, expected postoperative pain, anesthetic technique, duration of the surgery, duration of hospital admission, postoperative nausea, postoperative infection, postoperative analgesic use, surgery during the first postoperative year, and postoperative quality of life, were all nonsignificant in the univariate logistic regression and were

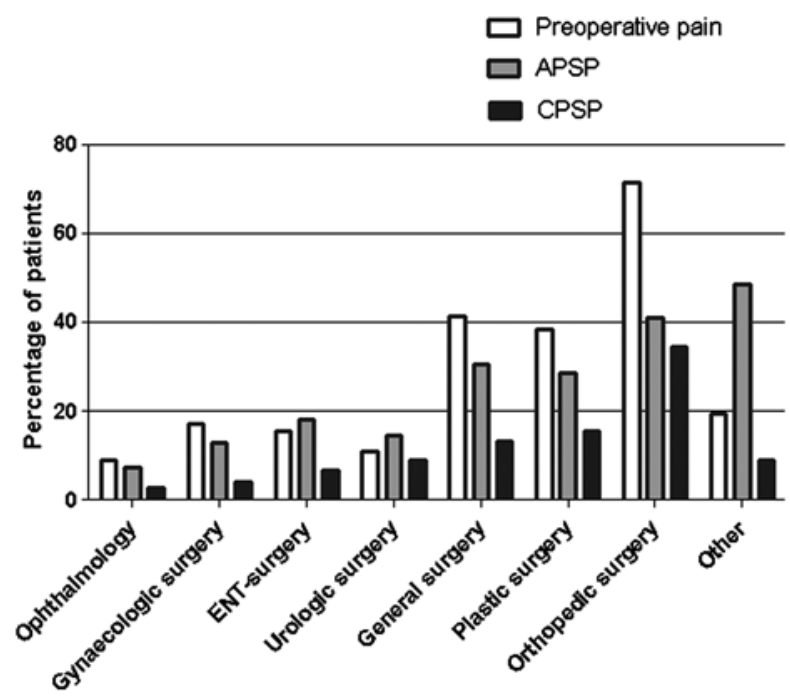

FIGURE 2. Prevalence of preoperative, acute postoperative, and chronic postoperative pain according to type of surgery. Percentage of patients with a numeric rating scale $>3$. APSP indicates acute postsurgical pain; CPSP, chronic postsurgical pain. therefore not included in this model. The most important predictors for CPSP after outpatient surgery were the surgical specialty, preoperative pain, preoperative analgesic use, surgical fear, and acute postsurgical pain. Of the patients with preoperative analgesic use and no preoperative pain (which is assumed to be adequately treated preoperative pain), the prevalence of CPSP was $8.0 \%$ as opposed to $32.0 \%$ for patients with moderate to severe preoperative pain (assumed to be inadequately treated preoperative pain). Higher optimism and higher preoperative quality of life were significant protective factors for the development of CPSP.

\section{Prevalence of Poor Global Recovery}

The average GSR index 1 year after outpatient surgery was $84.6 \%(\mathrm{SD}=25.1 \%)$. A total of 199 patients $(22.3 \%)$ scored a GSR of $\leq 80 \%$ and were thus defined as poor global recovery. Surgical specialties that were most often associated with poor global recovery were orthopedic surgery (ie, GSR $\leq 80 \%$ in $39.2 \%$ of the patients), plastic surgery $(24.7 \%)$, ophthalmologic surgery $(22.9 \%)$, earnose-throat surgery $(21.8 \%)$, urologic surgery $(20.0 \%)$, and general surgery $(17.8 \%)$. Gynecologic surgery was least often associated with poor global recovery, only $5.9 \%$ of these patients scored a GSR $\leq 80 \%$.

\section{Predictors of Poor Global Recovery}

ASA-level, work status, expected postoperative pain, pain catastrophizing, anesthetic technique, duration of surgery, duration of hospital admission, postoperative nausea, postoperative infection, and postoperative analgesic use were not statistically significant in the univariate logistic regression analysis and where not included in the final model. Significant predictors for poor global recovery were the surgical specialty (ie, orthopedic surgery), preoperative pain, preoperative analgesic use, poor global recovery 4 days postoperative, surgical fear, related surgery during the year before the index surgery, and follow-up surgery during the first postoperative year. Furthermore, higher preoperative and postoperative quality of life, as well as higher optimism, protected against a poor global recovery.

\section{Correlation Analysis}

Because the data for CPSP and GSR were not parametric, a Spearman $\rho$ was performed to determine the correlation between CPSP and GSR. The correlation coefficient was $-0.656(P<0.001)$. Furthermore, patients without CPSP have a median GSR index of $100 \%$ (interquartile range, $90 \%$ to $100 \%$ ), and patients with CPSP have a median GSR index of 50\% (interquartile range, $25 \%$ to $75 \%$ ).

\section{DISCUSSION}

In our study, $15.3 \%$ of all patients experienced moderate to severe CPSP after outpatient surgery, and 2.3\% experienced severe CPSP. These findings fall in the range of the prevalences previously reported in several review papers. Kehlet et al ${ }^{11}$ reported a prevalence of $10 \%$ to $50 \%$ moderate to severe CPSP and $2 \%$ to $10 \%$ severe CPSP. Another review article reports even higher incidences; $15 \%$ to $60 \%$ for moderate to severe CPSP and $4 \%$ to $10 \%$ for severe disabling CPSP. ${ }^{15} \mathrm{~A}$ recent publication researching only general surgical procedures, reported an incidence of $14.8 \%$ for moderate to severe CPSP. ${ }^{27}$ However, these and 
TABLE 3. Results of the Logistic Regression Analysis for CPSP (Numeric Rating Scale $>3$ ) and Poor Global Recovery (Global Surgical Recovery Index $\leq 80 \%$ )

\begin{tabular}{|c|c|c|c|c|}
\hline Independent Variables & $\begin{array}{c}\text { Chronic Postsurgical Pain } \\
\text { OR }(95 \% \text { CI })\end{array}$ & $\mathbf{A U C}$ & $\begin{array}{c}\text { Poor Global Surgical Recovery } \\
\text { OR }(95 \% \text { CI })\end{array}$ & $\mathbf{A U C}$ \\
\hline Step 1 & & 0.73 & & 0.65 \\
\hline \multicolumn{5}{|l|}{ Age } \\
\hline Old vs. young & $0.99(0.98-1.00)$ & & $1.00(0.99-1.01)$ & \\
\hline \multicolumn{5}{|l|}{ Sex } \\
\hline Male vs. female & $0.82(0.55-1.21)$ & & $0.85(0.62-1.16)$ & \\
\hline \multicolumn{5}{|l|}{ Surgical specialty (vs. ophthalmology) } \\
\hline Gynecology & $1.21(0.48-3.09)$ & & $0.37(0.15-0.90)$ & \\
\hline Ear-nose-throat surgery & $2.24(0.75-6.74)$ & & $0.83(0.42-1.61)$ & \\
\hline Urology & $3.50(1.48-8.28)$ & & $0.84(0.55-1.27)$ & \\
\hline General surgery & $4.97(2.37-10.42)$ & & $0.86(0.64-1.16)$ & \\
\hline Plastic surgery & $5.89(2.72-12.75)$ & & $1.14(0.80-1.61)$ & \\
\hline Orthopedic surgery & $16.41(3.88-69.34)$ & & $2.67(1.96-3.62)$ & \\
\hline Other & $2.65(0.35-20.16)$ & & $0.27(0.12-0.59)$ & \\
\hline Step 2 & & 0.80 & & 0.71 \\
\hline \multicolumn{5}{|l|}{ Educational level } \\
\hline Middle vs. low & & & $1.60(0.83-3.10)$ & \\
\hline High vs. low & & & $0.91(0.42-1.95)$ & \\
\hline \multicolumn{5}{|l|}{ Previous surgery } \\
\hline Not related & & & $1.40(0.86-2.30)$ & \\
\hline Related & & & $1.91(1.25-2.92)$ & \\
\hline \multicolumn{5}{|l|}{ Preoperative pain (numeric rating scale $>3$ ) } \\
\hline Yes vs. no & $4.22(2.54-7.02)$ & & $1.78(1.22-2.58)$ & \\
\hline \multicolumn{5}{|l|}{ Preoperative analgesic use } \\
\hline Yes vs. No & $2.16(1.40-3.34)$ & & $1.52(1.05-2.21)$ & \\
\hline Step 3 & & 0.85 & & 0.75 \\
\hline \multicolumn{5}{|l|}{ Surgical fear-long term } \\
\hline Per point (range, $0-40$ points) & $1.04(1.01-1.06)$ & & $1.03(1.01-1.05)$ & \\
\hline \multicolumn{5}{|l|}{ Optimism (Life Orientation Test) } \\
\hline Per point (range, $0-20$ points) & $0.90(0.82-0.98)$ & & $0.89(0.83-0.95)$ & \\
\hline \multicolumn{5}{|l|}{ Preoperative QoL (EQ-5D) } \\
\hline Per point (range, $0.59-1.00$ points) & $0.09(0.04-0.22)$ & & $0.30(0.14-0.67)$ & \\
\hline Step 4 & & 0.85 & & 0.78 \\
\hline \multicolumn{5}{|c|}{ Acute postsurgical pain (numeric rating scale $>3$ ) } \\
\hline Yes vs. no & $1.62(1.02-2.58)$ & & & \\
\hline \multicolumn{5}{|c|}{$\begin{array}{l}\text { Poor Global Surgical Recovery } 4 \mathrm{~d} \text { postoperative } \\
\text { (Global Surgical Recovery } \leq 80 \% \text { ) }\end{array}$} \\
\hline Yes vs. no & & & $2.41(1.44-4.04)$ & \\
\hline \multicolumn{5}{|l|}{ Surgery during first postoperative year } \\
\hline Not related & & & $0.72(0.26-1.94)$ & \\
\hline Related & & & $2.64(1.27-5.49)$ & \\
\hline \multicolumn{5}{|c|}{ Acute postoperative Quality of Life (EQ-5D) } \\
\hline Per point (range, $0.59-1.00$ points) & & & $0.24(0.12-0.50)$ & \\
\hline
\end{tabular}

Step 1 used a forced entry method, whereas in the other steps only significant variables (univariate $P<0.1$ ) are entered. Odds ratio (OR) with $95 \%$ confidence interval (CI) and area under the curve (ACU) are presented per step.

several other papers mostly describe surgical procedures that are usually not performed on an outpatient basis (eg, limb amputation, thoracotomy, coronary artery bypass surgery, cesarean section). ${ }^{11,14,15,28,29}$ So far, large-scale studies on CPSP after outpatient surgery are lacking; only relatively small studies focusing on specific outpatient procedures are available. There is reason to assume that both the prevalence and predictors of CPSPS might be different in outpatients as compared with inpatients. Inpatient procedures are often associated with more extensive tissue damage, longer duration of hospital admission, and a longer recovery period. In addition, the treatment of postoperative pain for outpatients might not be as optimal as for inpatients. ${ }^{16,17}$ Despite these dissimilarities the prevalence of CPSP found in the present study seems to be comparable with the ones reported for inpatient surgery.
One surgical procedure that has been extensively studied in the context of CPSP is inguinal hernia repair. The prevalence of CPSP for these procedures was $13.1 \%$ in our study, which is within the range reported by other studies $(5 \%$ to $35 \%){ }^{11,14,28,30,31}$ One potentially important predictor for the development of CPSP after inguinal hernia repair, is the surgical technique (eg, mesh vs. nonmesh, open vs. laparoscopic). ${ }^{30,32}$ Unfortunately, our study did not include and document data about the various surgical techniques.

The prevalence of CPSP after breast surgery has also been extensively studied. We found a CPSP prevalence of $10 \%$ after breast surgery, which contrasts to $20 \%$ to $50 \%$ reported in other major studies. ${ }^{11,14,28,33}$ Most studies have examined CPSP after surgery for breast cancer (ie, mastectomies and lumpectomies). The procedures in our study, 
however, were lumpectomies $(n=37)$, a few mastectomies $(\mathrm{n}=8)$, and the remaining were cosmetic surgical procedures $(\mathrm{n}=25)$. A small retrospective study focusing uniquely on cosmetic breast augmentation, found a CPSP prevalence of $9.5 \%{ }^{34}$ This might indicate that CPSP is more frequent after surgery for breast cancer than after cosmetic breast surgery. This might be explained by the fact that surgery for breast cancer is often associated with axillary surgery (ie, nerve damage), chemotherapy, and radiotherapy, all of which are risk factors for the development of CPSP. ${ }^{14,33}$

A third outpatient procedure that has previously been studied in the context of CPSP is cholecystectomy. In our population, CPSP occurred in $9.6 \%$ of the patients after general abdominal procedures and in $10 \%$ of patients after laparoscopic cholecystectomy. This is in line with the $5 \%$ to $50 \%$ previously reported. ${ }^{14,35}$

In addition to reporting the prevalence of CPSP after outpatient procedures, another major aim of our study was to identify predictors of CPSP after outpatient surgery. Previous studies on risk factors for the development of CPSP have mostly dealt with inpatient procedures. ${ }^{11,14}$ As mentioned above, the factors identified for these procedures may not necessarily be the same as those for outpatient procedures. To identify the factors that were related to the presence of CPSP, we performed a stepwise logistic regression analysis. The first step in logistic regression model contained easily obtainable variables, such as age, sex, and surgical specialty. In our model these 3 variables were capable of a reasonably adequate prediction $(\mathrm{AUC}=0.73$, which was mostly dependent on the surgical specialty. Orthopedic surgery was associated with the most severe CPSP. Orthopedic procedures are often associated with preoperative pain (which is often the reason to operate) and acute postoperative pain. These patients might therefore be prone to peripheral and central sensitization, which might cause the development of CPSP. Age and sex were not found to be significant predictors in our model. Previous studies found inconsistent evidence regarding age and sex as risk factors for CPSP, although various studies suggest that higher age may be associated with a decreased chance of developing CPSP. ${ }^{11,14,36}$

The second step of our model contained variables that can be easily obtained during preoperative assessment. This step significantly improved our model to an AUC of 0.80 . The presence of moderate to severe preoperative pain was shown to be the most important predictor of the entire model. Most studies addressing CPSP have also demonstrated this association. ${ }^{14,18,30,36}$ A possible reason for this association is the fact that peripheral and central sensitization may develop more easily in patients with long lasting pain. The presence of CPSP after orthopedic procedures might, however, also be a continuation of the preoperative pain, especially when pain was the indication for the surgery and the surgery was unsuccessful. Another important predictor for CPSP in our model was preoperative analgesic use, which has also been demonstrated before. ${ }^{37}$ It may, however, not be the use of analgesics in itself that is predictive of CPSP, but rather the efficacy of preoperative analgesic use. Our study demonstrated that patients with preoperative analgesics but without preoperative pain experienced significantly less CPSP than patients with inadequately treated preoperative pain. Treating preoperative pain with the correct and sufficient dose of analgesics might thus be a way of decreasing the prevalence and severity of CPSP. More research on this topic is needed.
The third step of our logistic regression analysis slightly improved our model by adding the psychological variables. Psychological risk factors for the development of CPSP after inpatient surgery have been extensively studied and especially anxiety and pain catastrophizing have been demonstrated to be associated with the risk of developing CPSP. ${ }^{10,14,18}$ In our study, all psychological variables included were associated with CPSP in the univariate analyses. In the multivariate analysis, long-term surgical fear, optimism, and quality of life remained in the model. Pain catastrophizing was no longer significant in the multivariate analyses. It might be speculated that patients undergoing minor outpatient procedures are less prone to catastrophize compared with patients undergoing more extensive inpatient procedures. Another explanation might lie in the use of a shortened version of the Pain Catastrophizing Scale, which might be less reliable. An alternative interpretation for the different findings among studies might be that anxiety, pain catastrophizing, and optimism are to some extent correlated with each other. Letting them compete in a multivariate regression analysis might thus be artificial and lead to unstable results. In that case, another approach could be to identify broader psychological profiles, such as was done by Bruce et al. ${ }^{33} \mathrm{~A}$ composite variable consisting of high optimism, high positive affect, and low trait anxiety and depression, which they called "psychological robustness" was associated with a decreased risk of developing CPSP after breast cancer surgery.

The fourth step added all perioperative and postoperative variables. The only statistically significant predictor for CPSP after outpatient surgery in this step was the presence of acute postoperative pain. Acute postoperative pain has been reported to be an important predictor for CPSP in other studies. ${ }^{11,14,18,32}$ In our population acute postoperative pain also predicted CPSP, but our model improved only slightly. Hence, acute postoperative pain seems less important than preoperative pain in predicting CPSP. It might be speculated that neuroplastic changes related to the development of CPSP, like peripheral and central sensitization, are more extensive and severe after long lasting preoperative pain than after relatively brief acute postoperative pain.

In addition to identifying predictors for CPSP, we also examined predictors of global perceived recovery. Some predictors for poor global recovery were identical to those for CPSP. This is not surprising, as pain is part of overall functional recovery and the 2 outcomes showed a substantial correlation. Nevertheless some additional predictors were identified: related surgery in the year before the surgical procedure and follow-up surgery during the year after the procedure, as well as preoperative and postoperative quality of life. Undergoing multiple operations within a relatively short timeframe and already being in a suboptimal condition as indicated by lower quality of life scores, may negatively impact the recovery process. Our model for predicting poor global recovery was fairly good $(\mathrm{AUC}=0.76)$, even though all 14 steps were necessary to achieve this predictability. However, more research on this patient is needed.

Our study included all outpatient procedures performed in our hospital, which has led to a heterogeneous study population. However, so far hardly any research on CPSP in a general outpatient population had been performed and the aim of this study was to examine whether CPSP is an 
important problem in this population as well. The heterogeneity was statistically corrected for by adding the surgical specialty to the regression model. Unfortunately, the groups of patients were too small to perform separate regression analyses for all the different kind of procedures performed. The results do demonstrate that some procedures are more often associated with CPSP than others (eg, orthopedic surgery). However, when other possible predictors were added to the model, such as preoperative pain and analgesic use, the contribution of the surgical specialty became less prominent. This demonstrates that there may be common factors predicting outcome of various surgical procedures.

Our study has several limitations. The first limitation of our study might be that it is not possible to determine whether CPSP was a new problem or whether it was a continuation of already existing preoperative pain. The proposed definition of CPSP by Macrae ${ }^{9}$ states that this should be ruled out. Nevertheless, the aim of our study was to identify patients at risk for developing CPSP and preoperative pain seemed to be the single most important risk factor. For the individual patient is does not matter whether it is a new problem or not, they simply want to be able to prevent it or treat it. Future studies, however, should try to establish detailed assessment to determine whether the postsurgical pain is indeed newly developed pain. Another limitation is that patients were not asked to differentiate between pain at rest and pain with movement. Several previous studies have made this distinction and have shown that there can be a difference. ${ }^{33,35}$ We recommend that future studies do differentiate between pain at rest and pain with movement.

An important next step will be to investigate if and how it is possible to prevent CPSP, especially in patients at risk. As preoperative pain seems to be the single most important risk factor, one might hypothesize that a strategy of effectively treating this pain might reduce the incidence of CPSP. Whether it is possible to reverse the central sensitization that has already taken place, is a topic for future research. We feel that patients undergoing surgery should be informed that CPSP is an important problem, even after outpatient procedures and this information should be used as one of the determinants as to whether an elective surgical procedure should take place or not.

In conclusion, our study demonstrates that CPSP after outpatient surgery is an important problem, with $15.3 \%$ of all patients experiencing moderate to severe pain 1 year after the surgery. The preoperative phase proved to be extremely important in identifying patients at risk. By asking patients about preoperative pain and analgesic use, and determining the surgical specialty, it may be possible to reasonably accurately predict the chance of developing CPSP. This prediction might be somewhat improved by identifying patients with an unfavorable psychological profile, exemplified by a lack of optimism, high levels of surgical fear, and a low preoperative quality of life in this study. Although acute postoperative pain has previously been found to be an important risk factor, the addition of this factor only slightly improved our predictive model.

\section{REFERENCES}

1. Wu CL, Berenholtz SM, Pronovost PJ, et al. Systematic review and analysis of postdischarge symptoms after outpatient surgery. Anesthesiology. 2002;96:994-1003.

2. Rawal N. Postoperative pain treatment for ambulatory surgery. Best Pract Res Clin Anaesthesiol. 2007;21:129-148.
3. McGrath B, Elgendy H, Chung F, et al. Thirty percent of patients have moderate to severe pain $24 \mathrm{hr}$ after ambulatory surgery: a survey of 5703 patients. Can J Anaesth. 2004;51: 886-891.

4. Gramke HF, de Rijke JM, van Kleef M, et al. The prevalence of postoperative pain in a cross-sectional group of patients after day-case surgery in a university hospital. Clin J Pain. 2007;23:543-548.

5. Brattwall M, Warren Stomberg M, Rawal N, et al. Patients' assessment of 4-week recovery after ambulatory surgery. Acta Anaesthesiol Scand. 2011;55:92-98.

6. Beauregard L, Pomp A, Choiniere M. Severity and impact of pain after day-surgery. Can J Anaesth. 1998;45:304-311.

7. Gramke HF, de Rijke JM, van Kleef M, et al. Predictive factors of postoperative pain after day-case surgery. Clin $J$ Pain. 2009;25:455-460.

8. Ip HY, Abrishami A, Peng PW, et al. Predictors of postoperative pain and analgesic consumption: a qualitative systematic review. Anesthesiology. 2009;111:657-677.

9. Macrae WA. Chronic pain after surgery. Br J Anaesth. 2001; 87:88-98.

10. Theunissen HM, Peters ML, Bruce J, et al. Preoperative anxiety and catastrophizing: a systematic review and metaanalysis of the association with chronic postsurgical pain. Clin J Pain. 2012;28:819-841.

11. Kehlet H, Jensen TS, Woolf CJ. Persistent postsurgical pain: risk factors and prevention. Lancet. 2006;367:1618-1625.

12. Nickel R, Raspe HH. Chronic pain: epidemiology and health care utilization. Der Nervenarzt. 2001;72:897-906.

13. Parsons B, Schaefer C, Mann R, et al. Economic and humanistic burden of post-trauma and post-surgical neuropathic pain among adults in the United States. J Pain Res. 2013;6:459-469.

14. Macrae WA. Chronic post-surgical pain: 10 years on. $\mathrm{Br} J$ Anaesth. 2008;101:77-86.

15. Lavand'homme P. The progression from acute to chronic pain. Curr Opin Anaesthesiol. 2011;24:545-550.

16. Watt-Watson J, Chung F, Chan VW, et al. Pain management following discharge after ambulatory same-day surgery. $J$ Nurs Manag. 2004;12:153-161.

17. Solca M, Savoia G, Mattia C, et al. Pain control in day surgery: SIAARTI guidelines. Minerva Anestesiol. 2004;70:5-24.

18. Peters ML, Sommer M, de Rijke JM, et al. Somatic and psychologic predictors of long-term unfavorable outcome after surgical intervention. Ann Surg. 2007:245:487-494.

19. Sullivan MJ, Bishop SR. The Pain Catastrophizing Scale: development and validation. Psychol Assess. 1995;7:524-532.

20. Theunissen M, Peters ML, Schouten EG, et al. Validation of the Surgical Fear Questionnaire in adult patients waiting for elective surgery. PloS One. 2014;9:e100225.

21. Scheier MF, Carver CS, Bridges MW. Distinguishing optimism from neuroticism (and trait anxiety, self-mastery, and selfesteem): a reevaluation of the Life Orientation Test. J Pers Soc Psychol. 1994;67:1063-1078.

22. van Agt HM, Essink-Bot ML, Krabbe PF, et al. Test-retest reliability of health state valuations collected with the EuroQol questionnaire. Soc Sci Med. 1994;39:1537-1544.

23. Kleinbeck SV. Self-reported at-home postoperative recovery. Res Nurs Health. 2000;23:461-472.

24. Gerbershagen HJ, Rothaug J, Kalkman CJ, et al. Determination of moderate-to-severe postoperative pain on the numeric rating scale: a cut-off point analysis applying four different methods. Br J Anaesth. 2011;107:619-626.

25. Dihle A, Helseth S, Paul SM, et al. The exploration of the establishment of cutpoints to categorize the severity of acute postoperative pain. Clin J Pain. 2006;22:617-624.

26. van Buuren S, Boshuizen HC, Knook DL. Multiple imputation of missing blood pressure covariates in survival analysis. Stat Med. 1999;18:681-694.

27. Simanski CJ, Althaus A, Hoederath S, et al. Incidence of chronic postsurgical pain (CPSP) after general surgery. Pain Med. 2014;15:1222-1229. 
28. Niraj G, Rowbotham DJ. Persistent postoperative pain: where are we now? Br J Anaesth. 2011;107:25-29.

29. Reddi D, Curran N. Chronic pain after surgery: pathophysiology, risk factors and prevention. Postgrad Med J. 2014;90:222-227; quiz 6.

30. Aasvang EK, Gmaehle E, Hansen JB, et al. Predictive risk factors for persistent postherniotomy pain. Anesthesiology. 2010;112:957-969.

31. Bay-Nielsen M, Perkins FM, Kehlet $\mathrm{H}$, et al. Pain and functional impairment 1 year after inguinal herniorrhaphy: a nationwide questionnaire study. Ann Surg. 2001;233:1-7.

32. Aasvang E, Kehlet H. Chronic postoperative pain: the case of inguinal herniorrhaphy. Br J Anaesth. 2005;95:69-76.

33. Bruce J, Thornton AJ, Powell R, et al. Psychological, surgical, and sociodemographic predictors of pain outcomes after breast cancer surgery: a population-based cohort study. Pain. 2014; 155:232-243.

34. von Sperling ML, Hoimyr H, Finnerup K, et al. Persistent pain and sensory changes following cosmetic breast augmentation. Eur J Pain. 2011;15:328-332.

35. Bisgaard T, Rosenberg J, Kehlet H. From acute to chronic pain after laparoscopic cholecystectomy: a prospective followup analysis. Scand J Gastroenterol. 2005;40:1358-1364.

36. Katz J, Seltzer Z. Transition from acute to chronic postsurgical pain: risk factors and protective factors. Expert Rev Neurother. 2009;9:723-744.

37. Keller SM, Carp NZ, Levy MN, et al. Chronic post thoracotomy pain. J Cardiovasc Surg (Torino). 1994;35 (suppl 1): $161-164$. 